\title{
Nickel-Catalyzed anti-Selective Alkyne Functionalization Reactions
}

\author{
Sydney E. Bottcher \\ Lauren E. Hutchinson \\ Dale J. Wilger* (D)
}

Samford University, Department of Chemistry and Biochemistry, 800 Lakeshore Dr., Birmingham, AL 35229, USA

dwilger@samford.edu<smiles>[R]/C=C(/C)c1ccccc1</smiles><smiles>[R]C(C#C[2H])=C1CCOB1N</smiles>

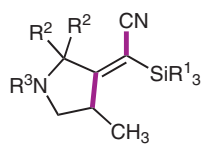<smiles>O=C1CC[C@@]2(O)C(Br)=C(Br)C[C@@]12Br</smiles><smiles>[R][C@@]1(C(=O)O)CC([Ga])=C([Ga])C1=O</smiles><smiles>O=C(O)/C(=C1\CCCC1P)c1ccccc1</smiles><smiles>Nc1c(Br)c(Br)c(O[AsH3])c2ccccc12</smiles><smiles>[R]/C(=C\S([R])(=O)=O)c1ccccc1</smiles>

Received: 30.03 .2020

Accepted after revision: 19.05 .2020

Published online: 22.06 .2020

DOI: 10.1055/s-0040-1707885; Art ID: ss-2020-m0170-sr

Abstract Nickel-catalyzed anti-selective alkyne functionalization reactions are reviewed with an emphasis on the mechanisms that lead to their observed stereoselectivity. Since the isomerization of alkenylnickel species plays a key role in a large number of these reactions, the potential mechanisms for these processes are also described in detail.

Introduction

anti-Selective Hydroarylation

anti-Selective Carboborylation

anti-Selective Dicarbofunctionalization

Carbocyanative Cyclization

4.2 Cyclization with Aryl Donors

4.3 Cyclization with $\mathrm{CO}_{2}$

4.4 Intermolecular Dicarbofunctionalization anti-Selective Carbosulfonylation

Alkenylnickel Isomerization Conclusions

Key words alkyne difunctionalization, Ni-catalyzed, cross-coupling, anti-selective, mechanistic studies, alkenylnickel

\section{Introduction}

Transition-metal-catalyzed alkyne hydro- and difunctionalization reactions are commonplace in modern synthetic chemistry. These reactions are popular because they produce synthetically relevant alkenes in a manner that is often regioselective and/or stereoselective. Because these reactions generally involve migratory insertion at the catalytic metal, syn selectivity is expected. A variety of different $\mathrm{Ni}$-catalyzed alkyne functionalization reactions have, however, demonstrated anti stereoselectivity. These reactions are highlighted in this Short Review (Scheme 1), and their mechanisms are described whenever possible. The antiselective reactions described in this review frequently (but

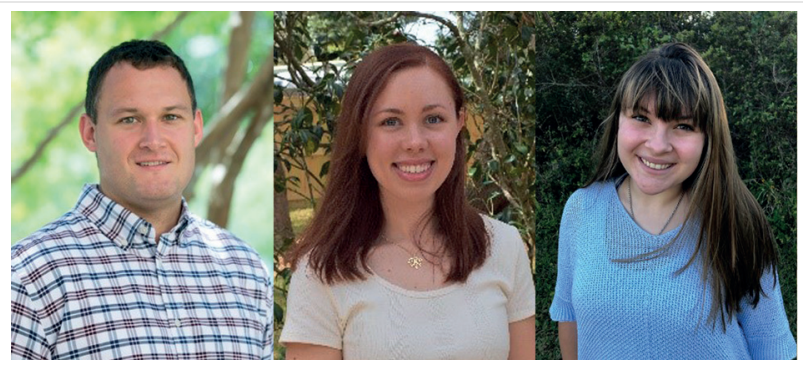

Dale Wilger (left) was born in 1984 in Buffalo, New York. He obtained his undergraduate degree in chemistry at Fredonia State. He pursued his graduate studies at the University of North Carolina at Chapel Hill within the lab of Professor Marcey Waters (2006-2011). After performing postdoctoral research with Professor David Nicewicz, he became a professor of chemistry at Samford University in Birmingham, Alabama (2015). Dr. Wilger's research interests include the development of novel $\mathrm{Ni}$-catalyzed cross-coupling reactions and mechanistic studies related to these important transformations.

Sydney Bottcher (middle) was born in 1999 in Ft. Benning, Georgia. In 2018, she began an undergraduate degree in chemistry and biochemistry at Samford University where she joined the group of Professor Dale Wilger. Her research focuses on anti-selective alkyne hydroarylation reactions and subsequent modifications to form triaryl alkenes.

Lauren Hutchinson (right) was born in 2000 in Orlando, Florida. After receiving her high school diploma from The Master's Academy, she went on to study chemistry and biochemistry at Samford University. Lauren joined the research group of Professor Dale Wilger in 2019. Lauren's research focuses on organometallic chemistry and the Ni-catalyzed synthesis of indenones.

not exclusively) rely on the isomerization of catalytic alkenylnickel intermediates. The penultimate section of this review focuses on the different mechanisms that can lead to alkenylnickel isomerization since these processes are a common unifying feature for many anti-selective alkyne functionalization reactions. 


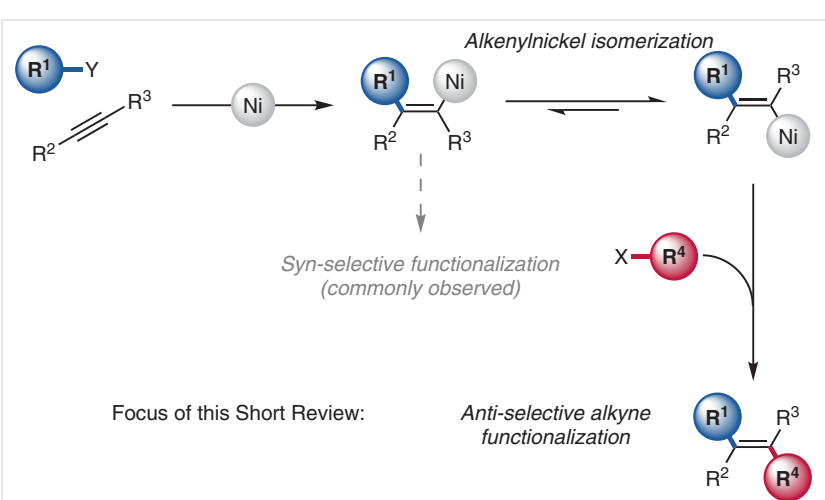

Scheme 1 Transition-metal-catalyzed alkyne hydroarylation reactions typically yield syn stereoselectivity

\section{2 anti-Selective Hydroarylation}

Transition-metal-catalyzed alkyne hydroarylation is a well-established approach for the stereoselective synthesis of alkenes. ${ }^{1}$ Catalytic systems employing $\mathrm{Cr},{ }^{2} \mathrm{Mn},{ }^{3} \mathrm{Fe},{ }^{4} \mathrm{Co},{ }^{5}$ $\mathrm{Ni}^{6}{ }^{6} \mathrm{Cu}^{7}{ }^{7} \mathrm{Rh},{ }^{8}$ and $\mathrm{Pd}^{9}$ have all been previously reported. Even though the mechanisms for these reactions vary, migratory insertion is often implicated as the key stereodefining step. Therefore, syn selectivity is commonly observed. ${ }^{2-}$ ${ }^{9}$ However, notable exceptions do exist. Fujiwara has reported an anti-selective alkyne hydroarylation reaction that directly activates $\mathrm{C}-\mathrm{H}$ bonds in aromatic compounds. ${ }^{10}$ The report by Fujiwara in 2000 was the first example of this reaction class to produce high anti stereoselectivity. ${ }^{10}$ More recently, several Au-catalyzed alkyne hydroarylation reactions have demonstrated comparable anti selectivity with similar substrates. ${ }^{11}$ This has helped to shed light on the mechanism of the Fujiwara hydroarylation, which likely proceeds through alkyne coordination and intermolecular nucleophilic attack by the arene (Wacker-type or FriedelCrafts-type mechanisms). ${ }^{11-13}$

Similar to Pd, Ni is well known for being able to provide syn-selective alkyne hydroarylations within a variety of substrate classes. ${ }^{14}$ Still, several different examples of antiselective alkyne hydroarylation have been reported within the last decade. In 2011, Robbins and Hartwig reported two different sets of conditions for Ni-catalyzed alkyne hydroarylation, both of which provided moderate anti stereoselectivity with certain substrates. ${ }^{15}$ Both sets of conditions required $\mathrm{Ni}(\operatorname{cod})_{2}$ as a precatalyst ( $\operatorname{cod}=1,5$-cyclooctadiene). The first preparation employed arylboronic acid derivatives 1 and diphenylacetylene $\mathbf{2}$ (Scheme 2). Triphenylphosphine was found to be the optimal supporting ligand under those conditions. Certain arylboronic acid derivatives with electron-withdrawing substituents provided trisubstituted alkenes $\mathbf{3}$ in high yields and high anti stereoselectivity. Clear trends regarding the observed anti stereoselectivity are challenging to identify. For example, ester and ketone groups at the para position of $\mathbf{1}$ provided low anti selectivi- ty (3b, 3c: ca. 3:1 Z/E), while an aldehyde and a nitrile group provided moderate and high anti selectivity, respectively (3f, 3g: 11.8:1 and >20:1 Z/E).
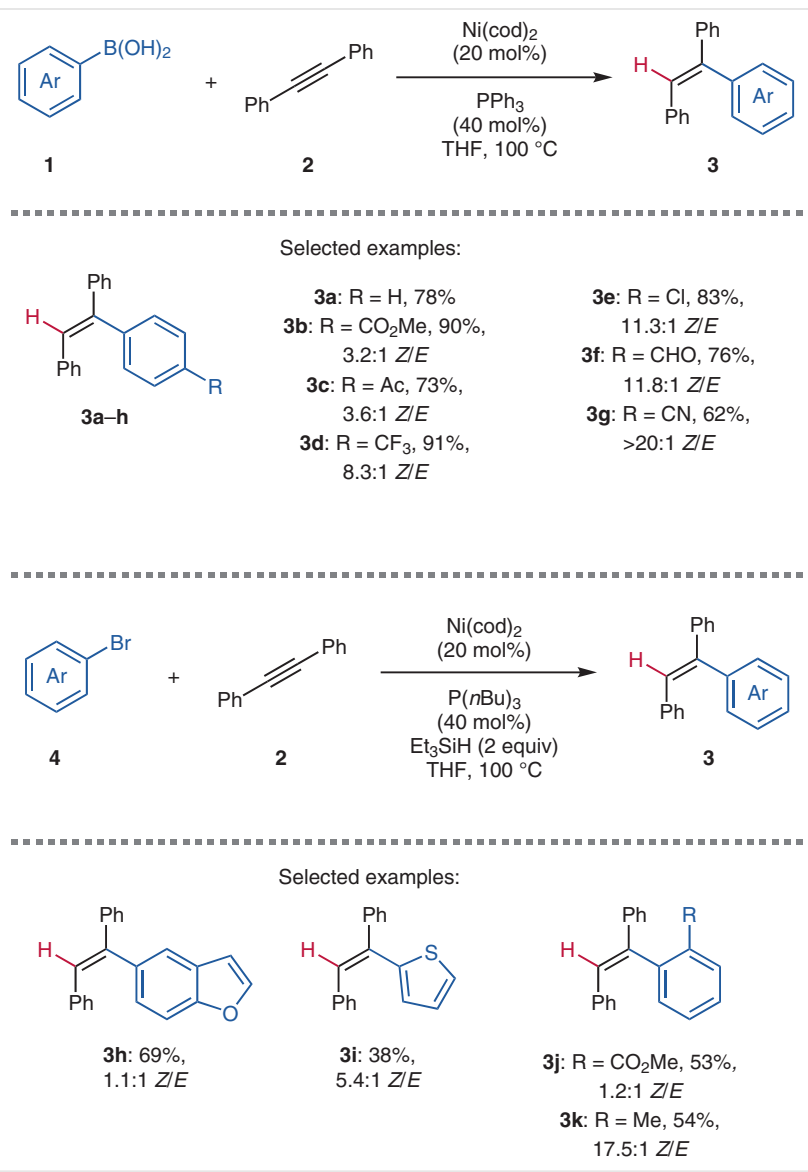

Scheme 2 Ni-catalyzed alkyne hydroarylation with arylboronic acids ${ }^{15}$

The second synthetic procedure reported by Robbins and Hartwig engaged aryl bromides 4 and required triethylsilane as an added reductant (Scheme 2). ${ }^{15}$ The optimal ligand in that preparation was tributylphosphine. The scope for this procedure was less extensive, but low to moderate anti stereoselectivity was observed when aryl bromides with ortho substituents were examined $(\mathbf{3 j}, \mathbf{k})$. The primary focus of this report by Robbins and Hartwig was a new method for the high-throughput discovery of transitionmetal-catalyzed reactions. A Cu-catalyzed oxidative (ChanLam) coupling reaction and a Cu-catalyzed alkyne hydroamination reaction were also reported. No potential mechanism for the hydroarylation reactions was discussed.

In 2017, Reddy et al. reported a Ni-catalyzed hydroarylation procedure for propargyl and homopropargyl alcohols (Scheme 3). ${ }^{16 a}$ Arylboronic acids served as the aryl donors. When terminal alkynes $\mathbf{5}$ were employed, hydroarylation products $\mathbf{6}$, with linear regioselectivity and syn stereoselectivity, were obtained. When otherwise similar internal alkynes $\mathbf{7}$ were examined, hydroarylation products $\mathbf{8}$ were 
isolated with the opposite regioselectivity and stereoselectivity. Reddy proposed a hydroarylation mechanism that operated entirely within the $\mathrm{Ni}(\mathrm{I})$ oxidation state. This proposed mechanism was based on findings previously reported by Liu (see below). ${ }^{17}$<smiles>[R]C(O)CC#CC</smiles>
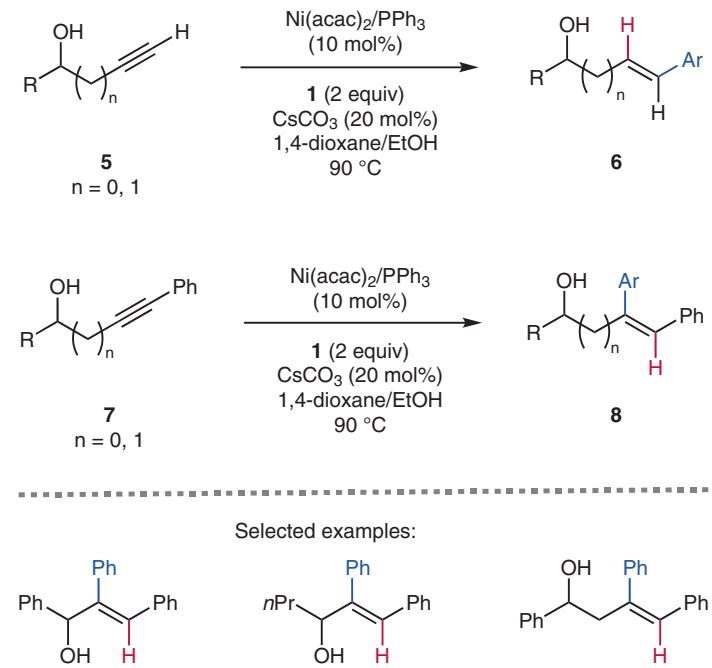

Selected examples:<smiles>CC(C)C(O)C(c1ccccc1)c1ccccc1</smiles><smiles>OC(C/C(=C/c1ccccc1)c1ccccc1)c1ccccc1</smiles>

8a: $67 \%$,
$9: 1$ ZIE 8 b: $70 \%$, 8c: $71 \%$,
$8.5: 1.5$ ZIE

Scheme 3 Hydroarylation with propargyl and homopropargyl alcohols $^{16}$

The mechanism described by Reddy et al. involved transmetalation, syn-selective migratory insertion to give $\mathbf{9}$, and protodenickelation to give $\mathbf{8}$ (Scheme 4). Interestingly, the change in regioselectivity observed for internal alkynes suggested that the orientation for migratory insertion depended on steric factors and not on directing group coordination, or at least that steric factors could override the stabilization provided by directing group coordination. Reddy proposed that isomerization of the alkenylnickel intermediate syn-9 allowed for the formation of the anti hydroarylation product. Coordination of the directing group to the metal center would stabilize anti-9 and provide the thermodynamic driving force for the observed stereoselectivity. This same rationale was provided by Cheng et al. to explain the anti stereoselectivity observed when propargylic substrates were employed in a Co-catalyzed alkyne hydroarylation procedure. ${ }^{18}$ In that report, Cheng et al. observed syn selectivity with nearly all other alkyne substrates. Both Cheng et al. and Reddy et al. reported no stereoselectivity $(1: 1 \quad Z / E)$ when alkynes lacking coordinating directing groups were examined. ${ }^{16,18}$

In 2019, Wilger et al. reported a Ni-catalyzed alkyne hydroarylation procedure that required only air-stable precatalysts, reagents, and substrates (Scheme 5; phen $=1,10$ phenanthroline). ${ }^{19}$ This reaction supplied trisubstituted alkenes 3 under operationally simple and inherently scalable conditions. Aryl bromides $\mathbf{4}$ served as aryl donors un-

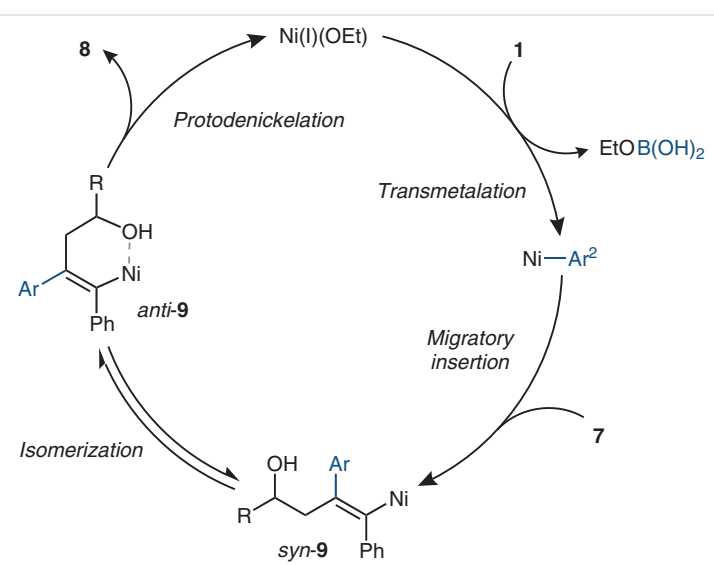

Scheme 4 Hydroarylation mechanism proposed by Reddy et al. ${ }^{16}$

der reductive conditions with $\mathrm{Zn}$ and water. Certain aryl bromides provided moderate anti stereoselectivity, similar to previous reports, although numerous substrates behaved differently. Aryl bromides with ortho substituents provided adequate anti stereoselectivity (31-p). Aryl bromides with meta substituents provided low anti stereoselectivity (3q,r). Aryl bromides with a para substituent provided good yields, but no measurable stereoselectivity $(1: 1 \mathrm{Z} / E)$. This stood in stark contrast to the report by Hartwig and Robbins, which recorded high anti stereoselectivity with several different para-substituted arylboronic acids. ${ }^{15}$

Wilger et al. performed deuterium-labeling experiments with $\mathrm{D}_{2} \mathrm{O}, d_{7}$-DMF, and $d_{8}$-toluene in order to better define the mechanism for Ni-catalyzed alkyne hydro-
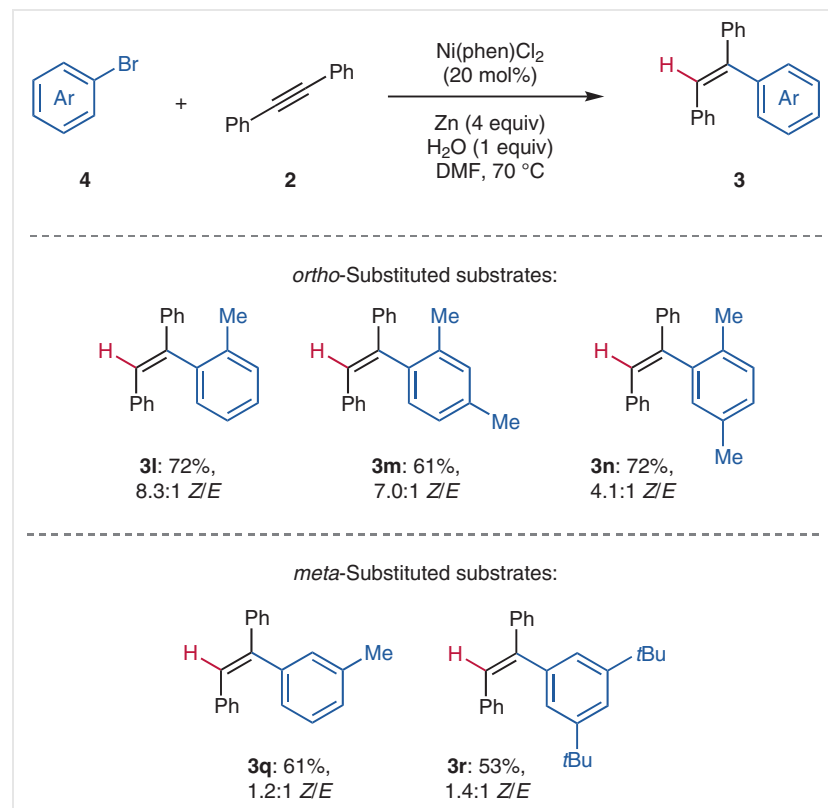

Scheme 5 Ni-catalyzed alkyne hydroarylation with air-stable reagents $^{19}$ 
arylation (Scheme 6). These experiments indicated that the vinyl hydrogen atom in $\mathbf{3}$ was primarily derived from added water. Small quantities (<20\%) of $\mathbf{3}$ were likely created via $\mathrm{Ni}-\mathrm{C}$ bond homolysis and hydrogen-atom transfer, especially under anhydrous conditions. The hydrogen atom donor was not the solvent under any of the conditions examined. Hydrogen atom abstraction most likely occurred from benzylic groups in $\mathbf{3}$ or $\mathbf{4}$ since added $d_{8}$-toluene could contribute to product deuteration.<smiles>Cc1ccccc1Br</smiles>

4 I<smiles>C#CPc1ccccc1</smiles>

2

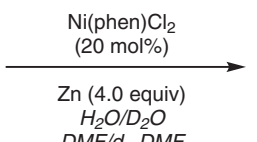

$D M F / d_{7}-D M F$

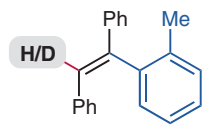

31

$\begin{array}{llll}\text { (1) } \mathrm{D}_{2} \mathrm{O}, \mathrm{DMF}: & 81 \% \mathrm{D} & \text { (4) } d_{7} \text {-DMF only: } & 0 \% \mathrm{D} \\ \text { (2) } \mathrm{H}_{2} \mathrm{O}, d_{7} \text {-DMF: } & 0 \% \mathrm{D} & \text { (5) } \mathrm{D}_{2} \mathrm{O}, \mathrm{DMF}, & \\ \text { (3) } \mathrm{D}_{2} \mathrm{O}, d_{7} \text {-DMF: } & 81 \% \mathrm{D} & 5 \text { equiv } \mathrm{C}_{6} \mathrm{D}_{5} \mathrm{CD}_{3}: & 87 \% \mathrm{D}\end{array}$

Scheme 6 Deuterium-labeling experiments for alkyne hydroarylation $^{19}$

Wilger et al. also performed mechanistic experiments with a $\mathrm{Ni}(\mathrm{II})$ aryl bromide complex, $\mathrm{Ni}\left({ }^{\mathrm{B} B u b p y}\right)($ o-tol)Br $\mathbf{1 0}$ (Scheme 7; 'Bubpy = 4,4'-di-tert-butyl-2,2'-dipyridyl). The complex 10 was competent as a precatalyst when compared to $\mathrm{Ni}\left({ }^{(} \mathrm{Bubpy}\right) \mathrm{Cl}_{2} \mathbf{1 1}$, indicating that a $\mathrm{Ni}(\mathrm{II})$ aryl halide complex is a likely catalytic intermediate. ${ }^{14 \mathrm{~d}}$ Stoichiometric experiments with $\mathbf{2}, \mathbf{4 1}$, and $\mathbf{1 0}$ indicated that $\mathrm{Zn}$ was required for adequate chemical yield. This suggested that at least one of the relevant catalytic intermediates exists in the $\mathrm{Ni}(\mathrm{I})$ oxidation state. ${ }^{14 d, 20}$ Additional mechanistic experiments indicated that an arylzinc intermediate was not likely. Other protic donors (such as $\mathrm{MeOH}, \mathrm{EtOH},{ }^{i} \mathrm{PrOH}$, and ${ }^{t} \mathrm{BuOH}$ ) gave similar $Z / E$ ratios, indicating that the diastereoselectivity of these reactions was not affected by the rate of protodenickelation.

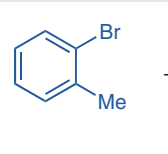

4

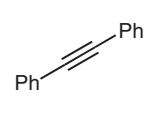

2

$20 \mathrm{~mol} \% \mathrm{Ni}\left({ }^{\text {(Bubpy })(o-t o l) B r}\right.$ (10): $20 \mathrm{~mol} \% \mathrm{Ni}(t \mathrm{Bubpy}) \mathrm{Cl}_{2}$ (11):

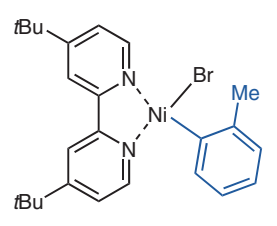

10

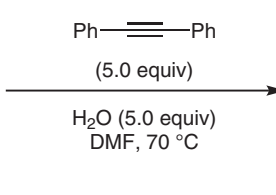

2.0 equiv $\mathrm{Zn}, 3 \mathbf{3}: 57 \%$
no $\mathrm{Zn}, \mathbf{3 1}: 18 \%$
Scheme 7 Mechanistic experiments with a Ni(II) aryl bromide complex $^{19}$
Wilger et al. proposed the mechanism shown below for $\mathrm{Ni}$-catalyzed alkyne hydroarylation (Scheme 8). ${ }^{19}$ Off cycle, the $\mathrm{Ni}(\mathrm{II})$ precatalyst is reduced to an active $\mathrm{Ni}(0)$ species $\mathbf{1 2}$ by $\mathrm{Zn}$. Oxidative addition into the $\mathrm{C}-\mathrm{Br}$ bond of 4 would produce an intermediate analogous to $\mathbf{1 0}$. Subsequent reduction with $\mathrm{Zn}$ and alkyne coordination would give a $\mathrm{Ni}(\mathrm{I})$ complex 13. Migratory insertion would produce syn-14. Isomerization of the alkenylnickel isomer syn-14 to anti-14 and protodenickelation would provide 3 , and the net effect of an anti-selective hydroarylation. Reduction of $\mathbf{1 5}$ by $\mathrm{Zn}$ would facilitate catalytic turnover. It has been shown that $\mathrm{Zn}$ is capable of reducing $\mathrm{Ni}(\mathrm{II})$ aryl halide complexes to $\mathrm{Ni}(\mathrm{I})$ aryl complexes. ${ }^{21}$ Therefore, Wilger et al. proposed that single-electron reduction occurs with $\mathbf{1 0}$ before migratory insertion and other subsequent steps. Since the complex $\mathbf{1 0}$ can produce non-negligible quantities of $\mathbf{3}$ without reductant, it may be possible that the requisite alkeneforming steps can occur from both the $\mathrm{Ni}(\mathrm{I})$ and $\mathrm{Ni}(\mathrm{II})$ oxidation states, but that product formation is faster from the $\mathrm{Ni}(\mathrm{I})$ oxidation state.

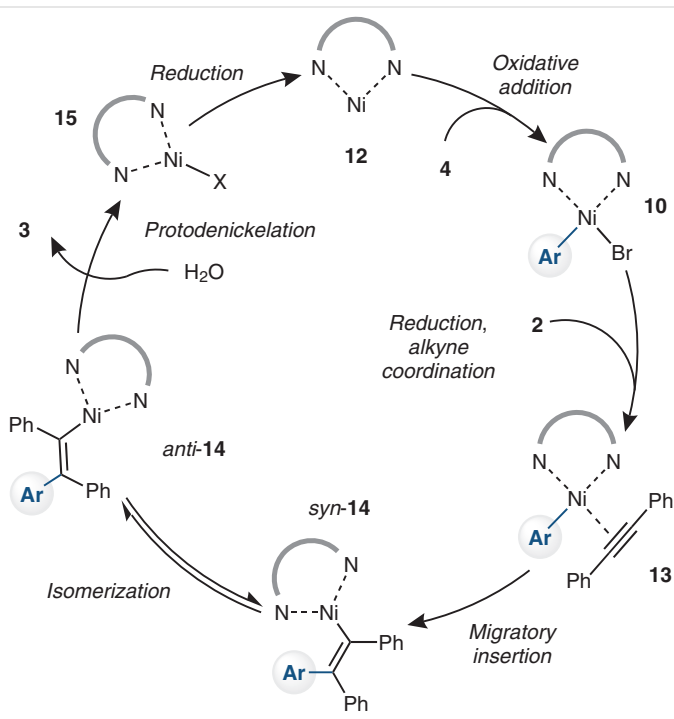

Scheme 8 Mechanism proposed for $\mathrm{Ni}$-catalyzed alkyne hydroarylation $^{19}$

The substrate scope for this reaction suggested that the thermodynamic driving force for isomerization was steric repulsion within the alkenylnickel intermediates syn-14 and anti-14. Aryl groups with ortho substituents are more sterically demanding, and equilibration through reversible isomerization would therefore tend to position these groups further away from the Ni center. This explains why ortho substituents on the aryl donors led to higher diastereoselectivity, while meta substituents led to low levels of selectivity, and para substituents led to no measurable selectivity. If the hydroarylation reaction reported by Hartwig and Robbins operates with a similar mechanism, then parasubstituted aryl donors may have provided better selectivity 
because phosphine ligands were used. Bipyridyl ligands are planar and possibly capable of rotating away from the substituted aryl group. Phosphine ligands are trigonal pyramidal and therefore present a greater three-dimensional steric profile. The observation that the more sterically hindered ${ }^{t}$ Bubpy ligand provided higher anti stereoselectivity compared to phenanthroline is consistent with this hypothesis. Steric repulsion is often implicated as the driving force for alkenylnickel isomerization in other catalytic reactions (see below).

\section{3 anti-Selective Carboborylation}

Organoboron compounds are viewed as some of the most versatile cross-coupling partners available to synthet-
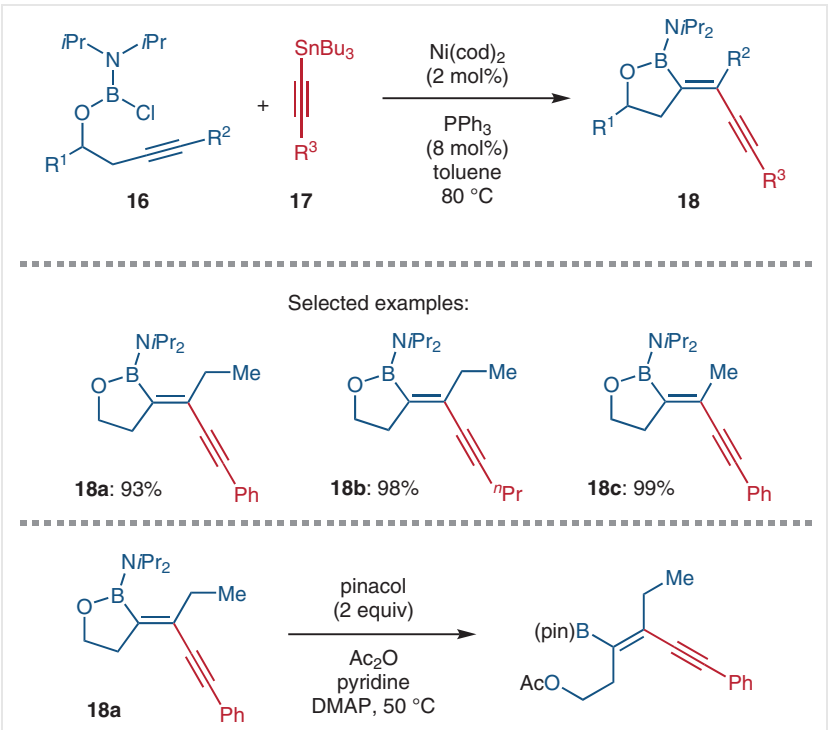

19a: $85 \%$
(based on $16 a)$

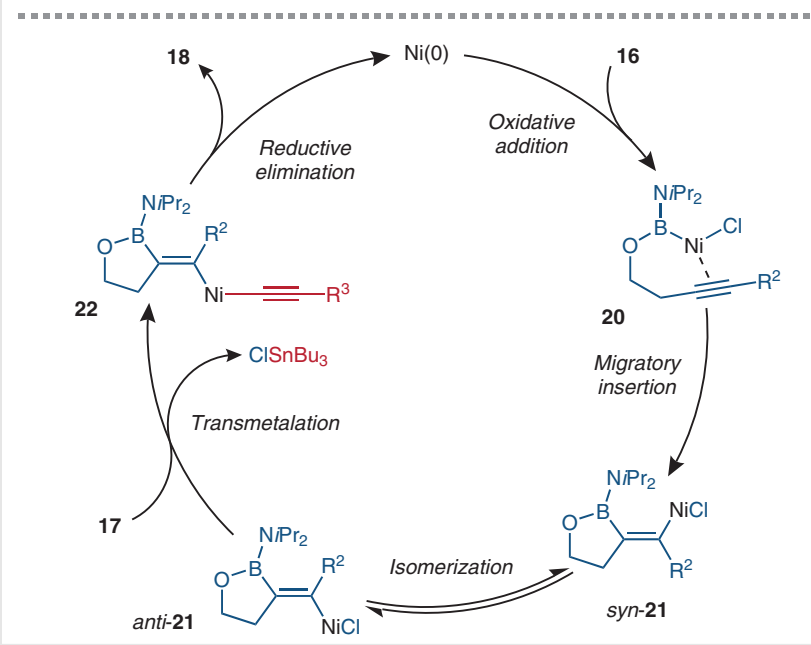

Scheme 9 Ni-catalyzed alkynylboration ${ }^{22}$ ic chemists. Aryl- and vinylboron reagents can be employed in a vast array of $\mathrm{C}-\mathrm{C}$ bond-forming reactions. This has led to an interest in synthesizing organoboron reagents with increasing functionalization. In 2005, Suginome et al. reported an anti-selective Ni-catalyzed alkynylboration reaction (Scheme 9). ${ }^{22}$ This cross-coupling was developed based on observations from a previously reported syn-selective cyanoboration reaction. ${ }^{23}$ Chloroboryl homopropargylic ethers $\mathbf{1 6}$ and alkynylstannanes $\mathbf{1 7}$ underwent clean 5-exo cyclization and carboboration across the alkyne triple bond, forming substituted alkene derivatives $\mathbf{1 8}$. The precatalyst used for this transformation was $\mathrm{Ni}(\operatorname{cod})_{2}$. Triphenylphosphine was found to be the optimal supporting ligand for catalytic reactions. The products $\mathbf{1 8}$ were moisture sensitive and were therefore converted into pinacolborane derivatives 19 before silica gel chromatography.

Suginome et al. proposed a mechanism that began with oxidative addition into the $\mathrm{B}-\mathrm{Cl}$ bond to give 20 . Migratory insertion of the alkyne into the $\mathrm{Ni}-\mathrm{B}$ bond would give syn21. Isomerization would produce anti-21, then transmetalation would produce $\mathbf{2 2}$, and reductive elimination would produce 18. Steric repulsion between the diisopropylamino group and the phosphine-ligated $\mathrm{Ni}$ center in syn-21 was proposed to drive the isomerization process. This hypothetical mechanism was strongly bolstered by the isolation and characterization of anti-21d, which was synthesized via a stoichiometric reaction between $\mathbf{1 6 d}, \mathrm{Ni}(\operatorname{cod})_{2}$, and the ligand $\mathrm{PMe}_{3}$ (Scheme 10). X-ray analysis of anti-21d clearly showed the trans configuration of the $\mathrm{C}-\mathrm{B}$ and $\mathrm{C}-\mathrm{Ni}$ bonds.

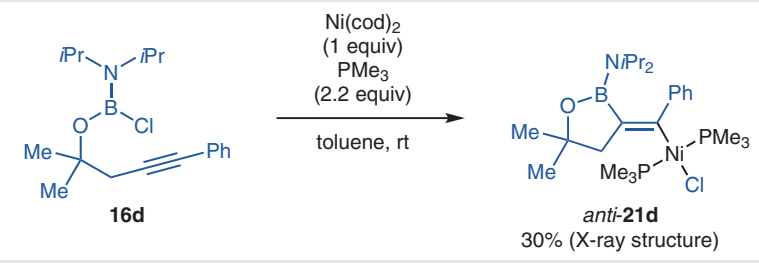

Scheme 10 Ni-catalyzed alkynylboration mechanism ${ }^{22}$

\section{4 anti-Selective Dicarbofunctionalization}

\subsection{Carbocyanative Cyclization}

In 2013, Arai et al. reported a Ni-catalyzed cyclative carbocyanation for enynes (Scheme 11). ${ }^{24}$ This procedure used $\mathrm{Ni}\left(\mathrm{P}(\mathrm{OPh})_{3}\right)_{4}$ as a precatalyst and acetone cyanohydrin as a HCN source. The enynes 23 underwent carbocyanative 5exo-cyclization to produce 24 . In certain cases, stoichiometric quantities of the $\mathrm{P}(\mathrm{OPh})_{3}$ ligand were found to be beneficial. When less sterically congested enynes were examined, 24 was obtained with low syn selectivity (3-5:1 Z/E). More sterically congested enynes gave $\mathbf{2 4}$ with very high anti selectivity (>20:1 E/Z). The substrate scope for this transformation was somewhat limited, but importantly, this study 

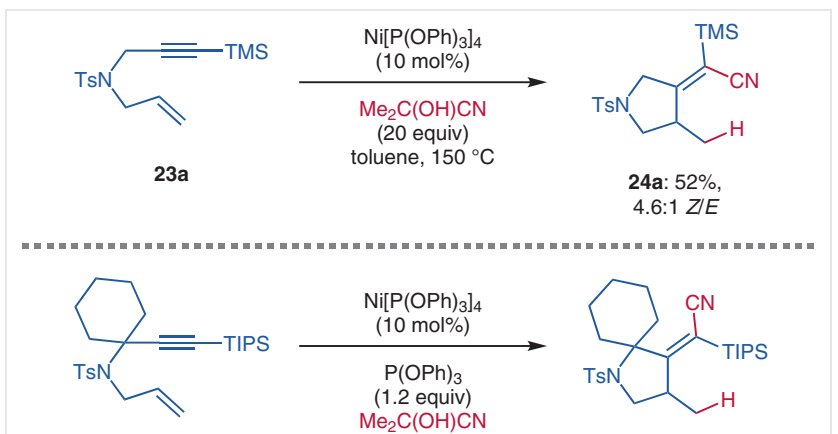

23b

(40 equiv) toluene, $150^{\circ} \mathrm{C}$

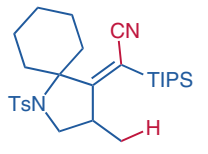

(E)-24b: $65 \%$

Scheme $11 \mathrm{Ni}$-Catalyzed carbocyanative cyclization of enynes ${ }^{24}$

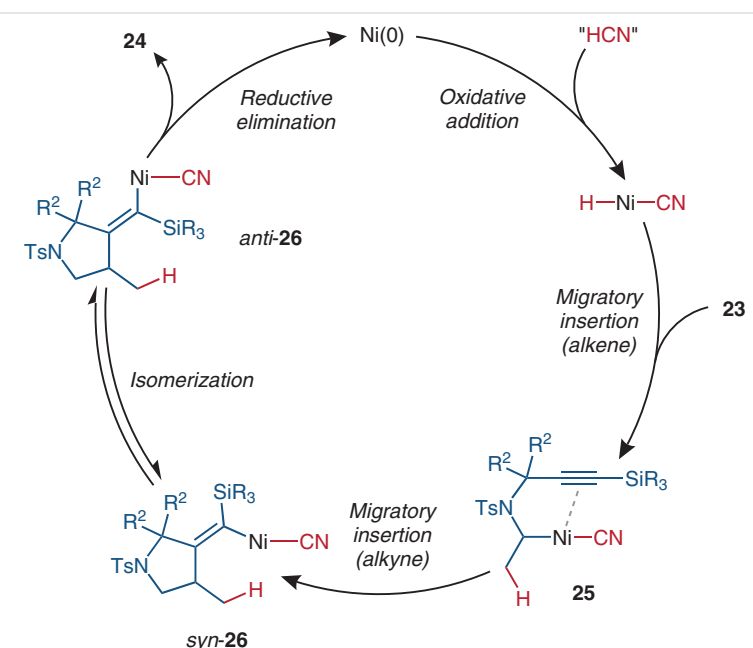

Scheme 12 Carbocyanative cyclization mechanism²4

provided the first example of an anti-selective carbocyanation.

Arai et al. proposed a mechanism beginning with oxidative addition of HCN or the cyanohydrin (Scheme 12). Migratory insertion of the alkene group in $\mathbf{2 3}$ would produce $\mathbf{2 5}$ and subsequent alkyne carbometalation would produce syn-26. Isomerization of the alkenylnickel intermediate syn-26 is likely driven by steric repulsion between the bulky silyl group and $\alpha$-substituents on the enyne scaffold. Reductive elimination of anti-26 would provide the product 24. Some evidence for migratory insertion of the alkene with the opposite regioselectivity (6-exo cyclization products) was observed during optimization. In addition to influencing alkenylnickel isomerization, bulky silyl groups were also necessary to discourage an initial migratory insertion of the more reactive $\mathrm{C}-\mathrm{C}$ triple bond, a reaction that did not result in cyclization.

\subsection{Cyclization with Aryl Donors}

In 2016, Liu et al. reported a Ni-catalyzed cyclization of alkynyl nitriles $\mathbf{2 7}$ to produce 1-naphthylamines $\mathbf{2 8}$ (Scheme 13). ${ }^{17}$ This transformation was necessarily facilitated by the isomerization of an alkenylnickel intermediate. Arylboronic acids $\mathbf{1}$ served as the aryl donors. Yields for the reaction were good when a wide variety of different arylboronic acids $\mathbf{1}$ and substituted alkynyl nitriles $\mathbf{2 7}$ were used. Arylboronic acids with either electron-donating or electron-withdrawing substituents were tolerated, as were sensitive functional groups such as ketones, esters, nitriles, and halides. A similarly wide scope was observed for substituents on 27, although alkyl substituents on the alkyne moiety resulted in substantially lower yields.

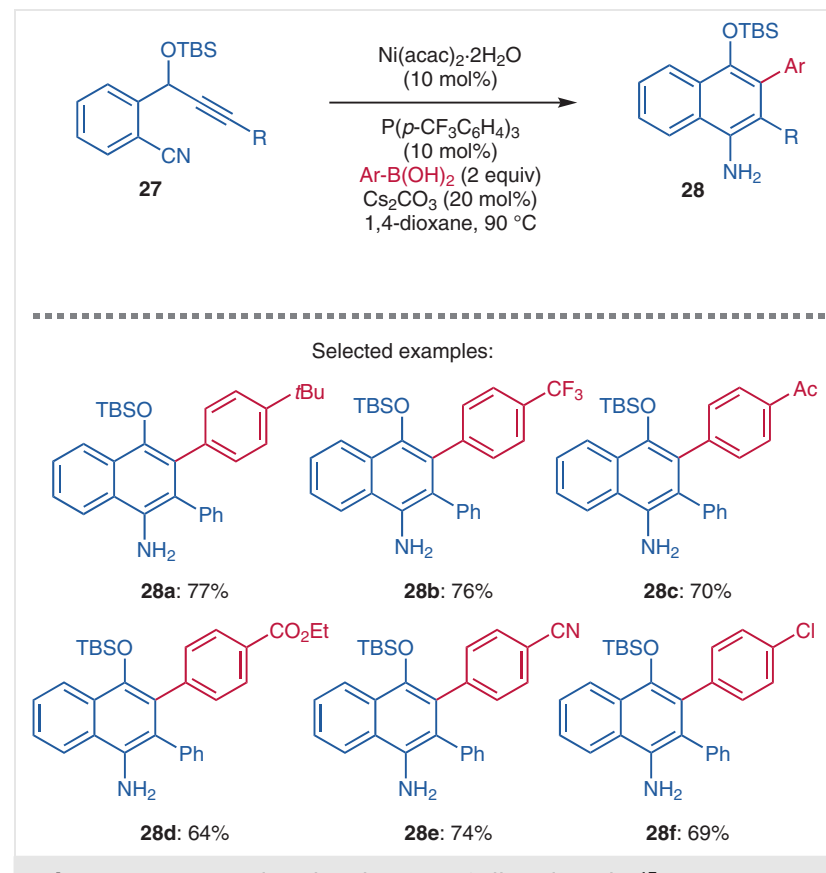

Scheme 13 Ni-Catalyzed cyclization of alkynyl nitriles ${ }^{17}$

Liu et al. performed several mechanistic experiments and found the Ni precatalyst $\mathrm{Ni}(\mathrm{acac})_{2}$, arylboronic acid $\mathbf{1}$, $\mathrm{KO}^{\mathrm{t}} \mathrm{Bu}$, and the ligand $\mathrm{IPr}$ produced a $\mathrm{Ni}(\mathrm{I})$ species $\mathrm{IPrNi}(\mathrm{acac})$ 29 (Scheme 14; IPr = 1,3-bis(2,6-diisopropylphenyl)imidazole-2-ylidene). The Ni(I) complex 29 was characterized by $\mathrm{X}$-ray analysis. The complex $\mathbf{2 9}$ was found to be catalytically competent (yield $=53 \%$ ) when compared to mixtures of $\mathrm{Ni}(\mathrm{acac})_{2}$ and the IPr ligand (yield $=64 \%$ ). This suggested that a $\mathrm{Ni}(\mathrm{I})$ complex analogous to $\mathbf{2 9}$ is a catalytic intermediate in the cyclization reaction.

Liu et al. proposed a catalytic mechanism that began with transmetalation to form a $\mathrm{Ni}(\mathrm{I})$ aryl species. Migratory insertion with the $\mathrm{C}-\mathrm{C}$ triple bond would produce syn-30. Isomerization to the alkenylnickel isomer anti-30 must occur before cyclization with the nitrile $\mathrm{C}-\mathrm{N}$ triple bond. 

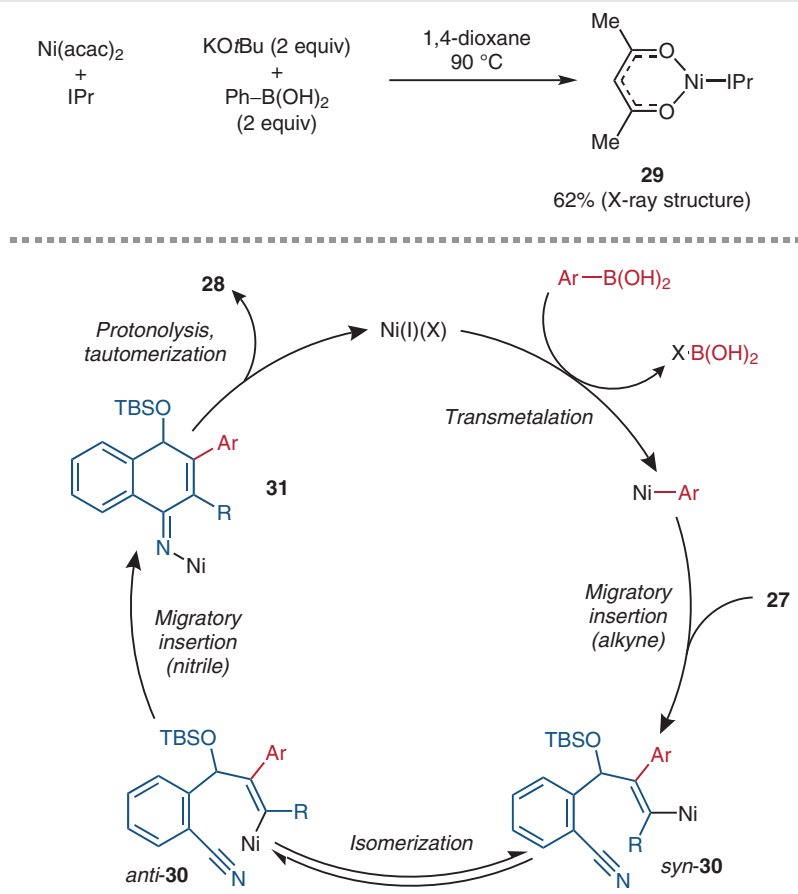

Scheme 14 Mechanism for Ni-catalyzed cyclization of alkynyl nitriles ${ }^{17}$

Protonolysis of $\mathbf{3 1}$ and tautomerization would produce $\mathbf{2 8}$. The regioselectivity of the alkyne migratory insertion step is critical to the transformation. Substrates lacking the OTBS group provided very low yields (ca. 10\%), implying that the substituent might play a role in directing the regioselectivity of alkyne migratory insertion. To our knowledge, this report by Liu was the first example of a catalytic reaction in which equilibrating alkenylnickel species are trapped via a cyclization event that is specific to the anti stereoisomer. Several other examples described below share this mechanistic feature.

In 2016, nearly concurrently with Liu's seminal example, Lam et al. reported a highly enantioselective catalytic cyclization reaction that was also facilitated by an alkenylnickel isomerization process (Scheme 15). ${ }^{25 a}$ Alkynyl 1,3diketones 32 underwent enantioselective cyclization with arylboronic acids $\mathbf{1}$ as aryl donors. The chiral bicyclic $\beta$-hydroxyketone products $\mathbf{3 4}$ were obtained with excellent yields and enantioselectivities when the phosphinooxazoline ligand 33 was used in conjunction with a $\mathrm{Ni}(\mathrm{OAc})_{2} \cdot 4 \mathrm{H}_{2} \mathrm{O}$ precatalyst. Lam et al. proposed a mechanism that began with transmetalation and alkyne migratory insertion to produce syn-35. The isomerization of syn$\mathbf{3 5}$ is driven by the removal of anti-35 from the reaction mixture via cyclization with the pendant carbonyl group. Protonation of the Ni alkoxide intermediate $\mathbf{3 6}$ provides the product 34 and catalyst turnover. Additionally, cyclohexane-1,3-diones 37 and cyclohexa-1,3-dienones 39 provided
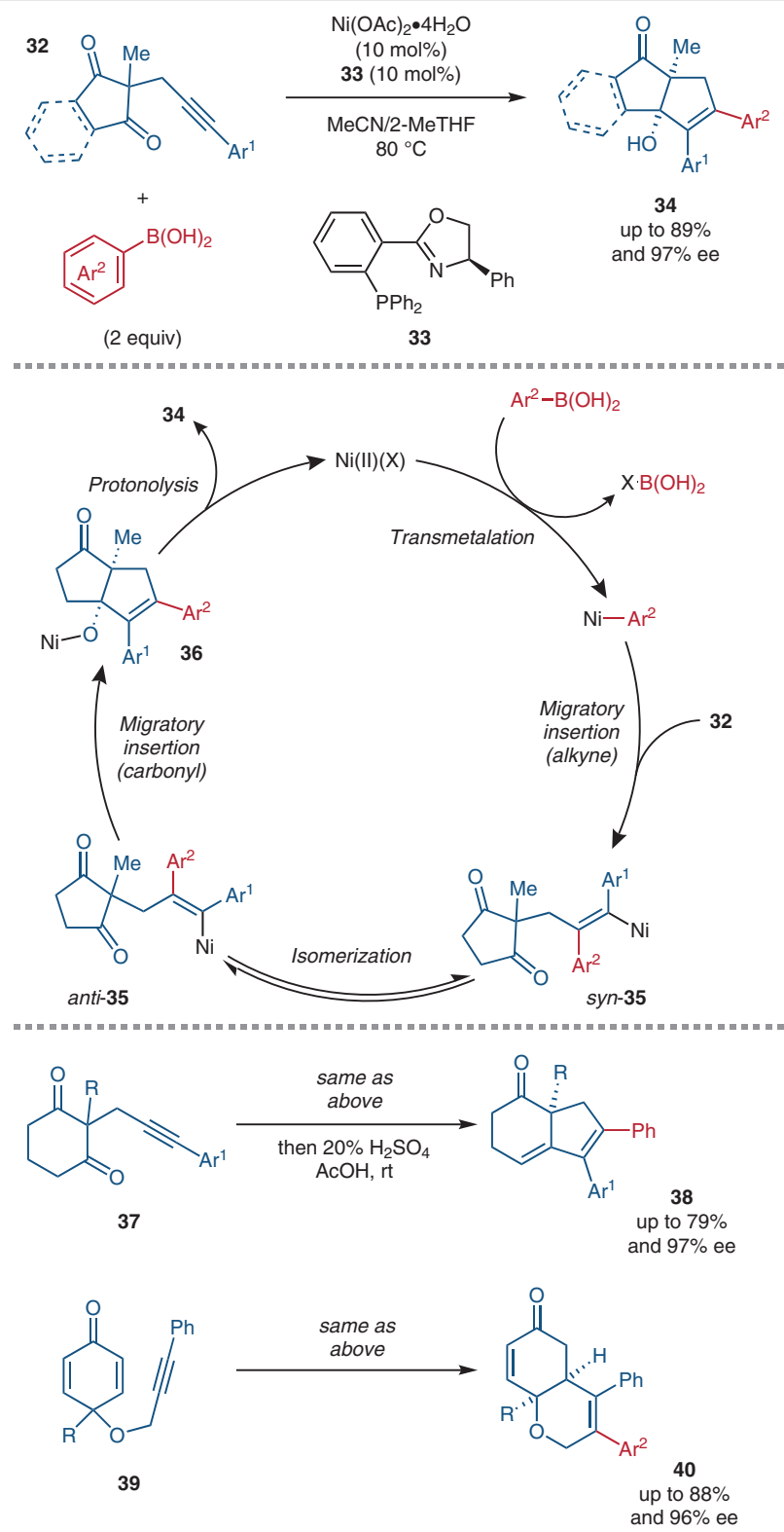

Scheme 15 Ni-Catalyzed cyclization of alkynyl ketones and enones ${ }^{25 a}$

the cyclic products $\mathbf{3 8}$ and $\mathbf{4 0}$, respectively, with high yields and enantioselectivities.

The Lam group has reported several other enantioselective cyclization reactions that operate with similar mechanistic principles (Scheme 16). In 2017, Lam et al. reported a $\mathrm{Ni}$-catalyzed cyclization with amine-tethered 1,6-enynes 41 and arylboronic acid donors 1 . In this case, $\mathrm{Ni}(\mathrm{OAc})_{2} \cdot 4 \mathrm{H}_{2} \mathrm{O}$ and the NeoPHOX ligand $\mathbf{4 2}$ provided cyclic amine products $\mathbf{4 3}$ with high yields and enantioselectivities. $^{25 \mathrm{~b}}$ The Z-configuration of the alkene moiety in $\mathbf{4 1}$ was found to be critical for cyclization to occur. In 2018, Lam et al. reported a Ni-catalyzed desymmetrization of propargyl- 
substituted malonate esters $\mathbf{4 4}$ to produce cyclic products 45. ${ }^{25 \mathrm{c}}$ The ligand 33 once again provided high yields and enantioselectivities. The substrate scope for the arylboronic acids and aryl alkynes was extensive in this report. This procedure allowed for gram-scale enantioselective syntheses. In 2018, Lam et al. reported a Ni-catalyzed cyclization for propargyl-substituted amides $\mathbf{4 6} .^{25 \mathrm{~d}}$ The pyrrole products 47 in this report were achiral, but yields were high and a wide variety of different aryl groups could be incorporated. All three reactions shown in Scheme 16 are proposed to occur through a similar mechanism involving transmetalation (from 1), regioselective and syn-selective alkyne migratory insertion, alkenylnickel isomerization, and cyclization of the anti alkenylnickel stereoisomer. In 2018, Reddy et al. reported a $\mathrm{Ni}$-catalyzed cyclization reaction for alkynyl azides that synthesized diarylquinolines in a closely related manner. ${ }^{16 \mathrm{~b}}$
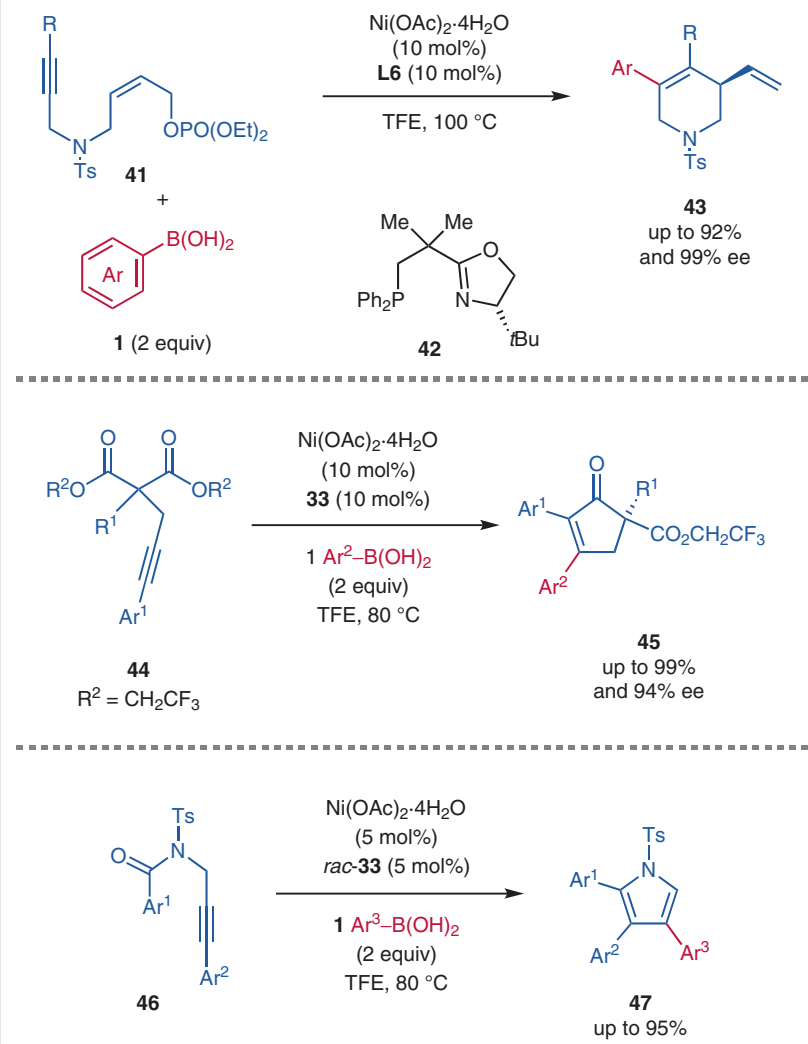

Scheme 16 Ni-Catalyzed cyclization of bifunctional substrates $25 b, c, d$

\subsection{Cyclization with $\mathrm{CO}_{2}$}

In 2015, Martin et al. reported a cyclative carboxylation for unactivated primary and secondary alkyl halides with $\mathrm{CO}_{2}$ (Scheme 17). ${ }^{26 a}$ As a $\mathrm{C} 1$ synthon, $\mathrm{CO}_{2}$ is ideal in terms of its cost, availability, and environmental impact. Martin et al. found that the precatalyst $\mathrm{NiBr}_{2}$.diglyme was effective in combination with bipyridyl ligands such as bathophenan- throline, bathocuproine, or neocuproine. Mn was used as a reductant. Primary alkyl bromides $\mathbf{4 8}$ provided syn-selective cyclization products 49 . Bathocuproine was found to be the optimal ligand for primary alkyl bromides. Secondary bromides $\mathbf{4 8}$ formed anti-selective cyclization products $\mathbf{4 9}$. Neocuproine was found to provide the highest anti selectivity when secondary alkyl bromides were employed. Similar to previously described examples, steric repulsion appeared to play a role in the diastereoselectivity of this transformation. Stoichiometric experiments with $\mathrm{Ni}(0)$ precursors provided no product, indicating that a simple $\mathrm{Ni}(0) / \mathrm{Ni}(\mathrm{II})$ catalytic cycle was not likely. Martin et al. proposed that a $\mathrm{Ni}(\mathrm{I})$ intermediate was relevant. The mechanism for alkenylnickel isomerization in this reaction is described in Section 6. In 2016, Martin et al. reported a related Ni-catalyzed carboxylation for unactivated primary, secondary, and even tertiary alkyl chlorides with $\mathrm{CO}_{2}, 26 \mathrm{~b}$ an impressive feat given the recalcitrant nature of these electrophiles in cross-coupling reactions. Several secondary alkyl chlorides demonstrated similar anti selectivity in that report as well. ${ }^{26 \mathrm{~b}}$
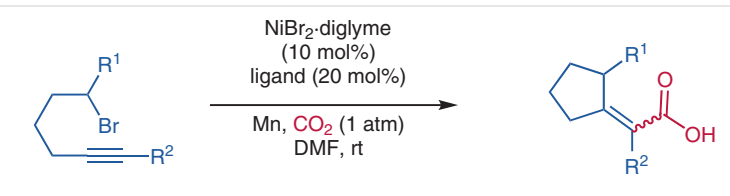

48

49

$\mathrm{R}^{1}=\mathrm{H}$ : syn-selectivity $\mathrm{R}^{1} \neq \mathrm{H}$ : anti-selectivity

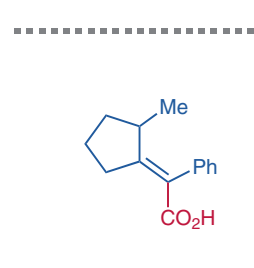

Selected examples:
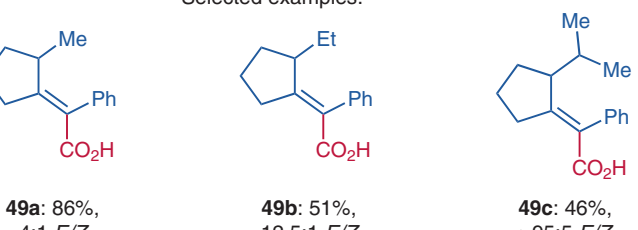

$4: 1 E / Z$

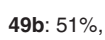

12.5:1 E/Z

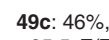

49c: $46 \%$,
$>95: 5 \mathrm{E} / \mathrm{Z}$

Scheme $17 \mathrm{Ni}$-Catalyzed cyclization and carboxylation with $\mathrm{CO}_{2}{ }^{26 a}$

\subsection{Intermolecular Dicarbofunctionalization}

The Nevado group has reported several intermolecular alkyne difunctionalization reactions that provide anti stereoselectivity through mechanisms that are distinct from those described above. ${ }^{27}$ In 2016, Nevado et al. reported that terminal alkynes $\mathbf{5 0}$, arylboronic acids $\mathbf{1}$, and alkyl halides $\mathbf{5 1}$ could serve as carbon-based building blocks for stereoselective alkene synthesis (Scheme 18). ${ }^{27 \mathrm{~b}}$ The chemical yields for alkenes $\mathbf{5 2}$ were good and the anti stereoselectivities were excellent (>99:1 in most cases). Moreover, the substrate scope for this cross-coupling was extensive. Even tertiary halides such as tert-butyl iodide could be used as alkyl donors within this procedure. Control experiments indicated that free radical inhibitors such as TEMPO or BHT 
halted reactivity. Reactions with both $\mathrm{Ni}(0)$ and $\mathrm{Ni}(\mathrm{II})$ precursors failed to provide vinyl halides without $\mathbf{1}$ or with substoichiometric quantities of $\mathbf{1}$. Nevado et al. hypothesized that a catalytic $\mathrm{N}(\mathrm{I}) / \mathrm{Ni}(\mathrm{III})$ cycle was operating. It was proposed that transmetalation with 1 would produce a $\mathrm{Ni}(\mathrm{I})$ aryl species $\mathbf{5 3}$ capable of intercepting 51. This reaction would generate a $\mathrm{Ni}(\mathrm{II})$ aryl halide species $\mathbf{5 4}$ and a carboncentered radical. The carbon-centered radical would add to the terminal alkyne $\mathbf{5 0}$ in an intermolecular fashion and produce a freely interconverting vinyl radical $\mathbf{5 5}$. Selective radical recombination of $\mathbf{5 5}$ with $\mathbf{5 4}$ would provide the $\mathrm{Ni}(\mathrm{III})$ complex $\mathbf{5 6}$ and explain the observed diastereoselectivity. Reductive elimination from $\mathbf{5 6}$ would furnish the product $\mathbf{5 2}$ and regenerate the $\mathrm{Ni}(\mathrm{I})$ catalyst.

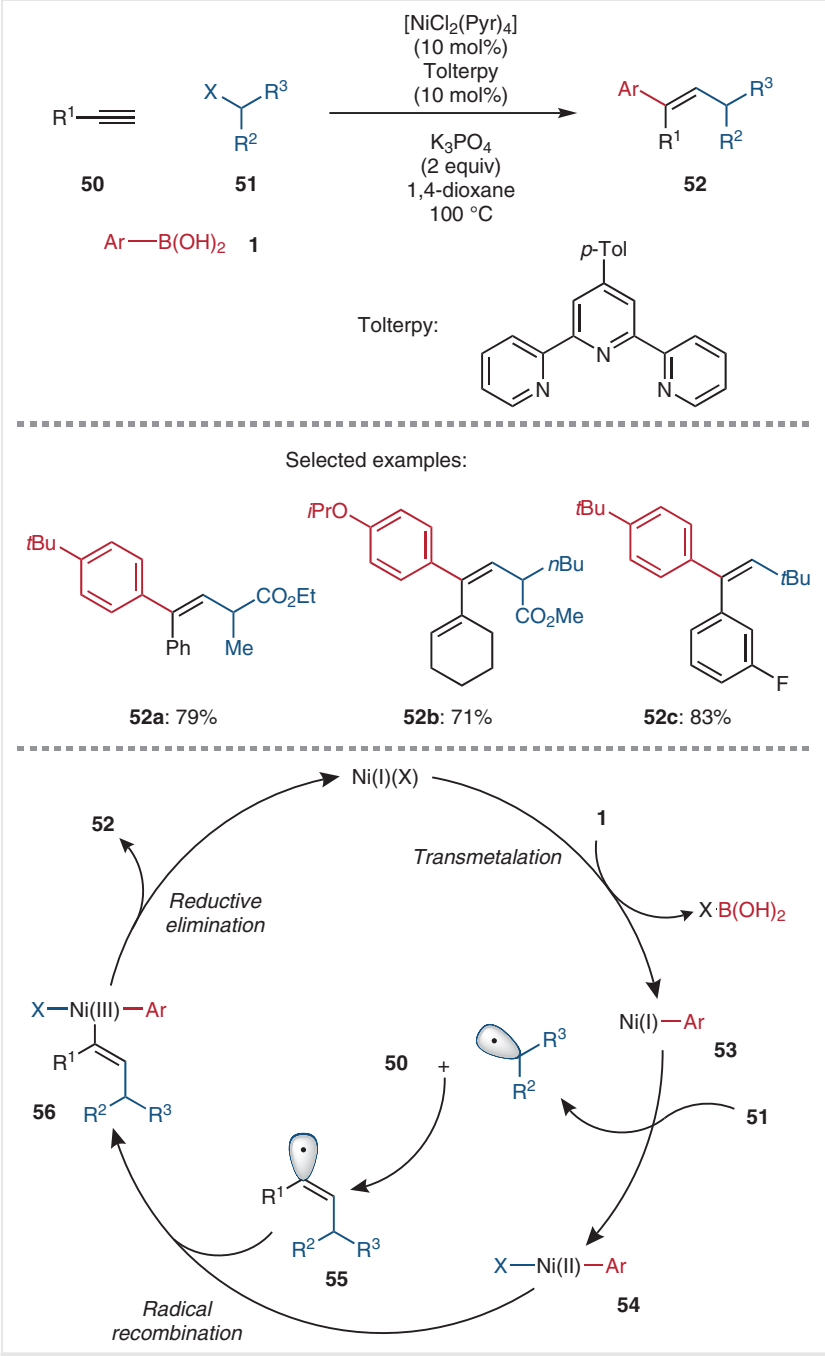

Scheme 18 Ni-Catalyzed dicarbofunctionalization ${ }^{27 b}$

\section{5 anti-Selective Carbosulfonylation}

In 2017, Nevado et al. reported a Ni-catalyzed anti-selective alkyne carbosulfonylation reaction (Scheme 19). ${ }^{27 c}$ Terminal alkynes $\mathbf{5 0}$, arylboronic acids $\mathbf{1}$, and sulfonyl chlorides $\mathbf{5 7}$ combined to produce highly substituted vinyl sulfones $\mathbf{5 8}$ in high yields and high anti stereoselectivities. In this case, a preformed catalyst with a unique ligand $\mathbf{5 9}$ was optimal (59 = 4,4',4"'-tri-tert-butyl-2,2':6',2"-terpyridine). The substrate scope for this reaction was broad. Nevado et al. proposed a mechanism very similar to the previously reported Ni-catalyzed dicarbofunctionalization reaction shown above (Scheme 18). A Ni(I) aryl complex was hypothesized to react with $\mathbf{5 7}$ to produce sulfonyl radicals. These sulfonyl radicals would add to $\mathbf{5 0}$ to generate freely interconverting vinyl radicals in much the same way. Selective recombination of these carbon-centered radicals with a $\mathrm{Ni}(\mathrm{II})$ aryl halide complex and reductive elimination would explain product formation and the observed diastereoselectivity. These alkyne difunctionalization mechanisms are unique compared to the other examples covered in this review. These reports have so far been limited to terminal alkynes, but the anti stereoselectivities have been exceptional. Similar approaches will likely be used to develop future anti-selective alkyne functionalization reactions.

\section{Alkenylnickel Isomerization}

Many of the anti-selective alkyne functionalization reactions described above rely on the isomerization of key alkenylnickel intermediates to provide adequate stereoselection. Numerous thermodynamic and kinetic factors influence the relative abundance of these alkenylnickel isomers, including steric repulsion, directing group coordination, and/or subsequent irreversible reactions. While these relationships that dictate the relative differences between alkenylnickel stereoisomers are often easily inferred, the kinetic factors that render one alkenylnickel species configurationally stable, and another configurationally labile, are more challenging to determine. It should be emphasized that $\mathrm{C}=\mathrm{C}$ double-bond isomerization is not inherent to all alkenylnickel species. Numerous syn-selective alkyne functionalizations and other cross-coupling reactions require alkenylnickel species that are configurationally stable. ${ }^{14,28}$ Understanding how alkenylnickel complexes undergo isomerization is highly important since it may allow further reaction development. Furthermore, in some cases the isomerization of alkenylnickel intermediates has led to the loss of stereochemical integrity. ${ }^{28}$ Therefore, there are compelling arguments for being able to both selectively facilitate and prevent alkenylnickel isomerization. It should also be emphasized that $\mathrm{C}=\mathrm{C}$ double-bond isomerization is not entirely unique to $\mathrm{Ni}$. Alkenylcobalt, ${ }^{18}$ alkenylruthenium, ${ }^{29}$ alkenylrhodium, ${ }^{30}$ alkenylpalladium, ${ }^{31}$ and alkenylosmium ${ }^{32}$ 

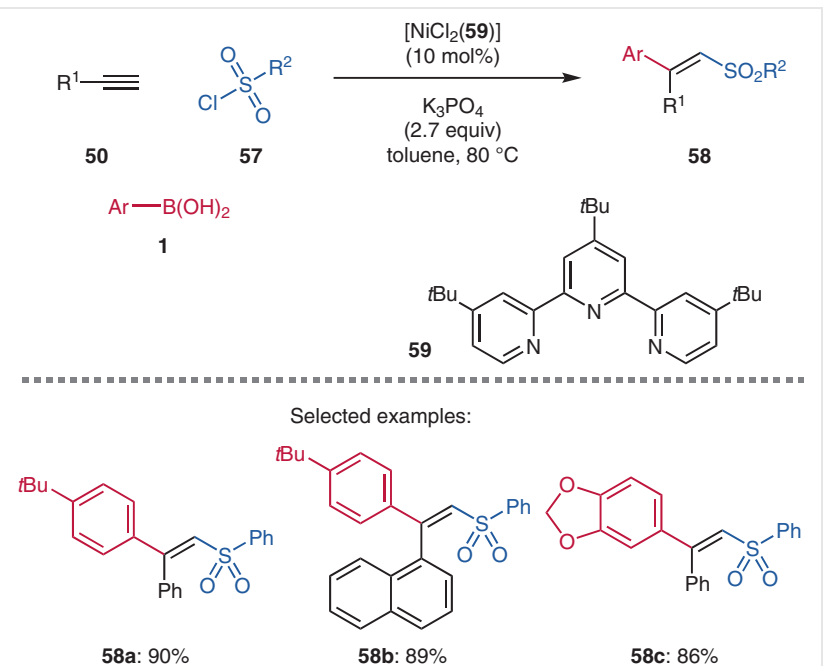

Scheme 19 Ni-Catalyzed carbosulfonylation ${ }^{27 c}$

complexes are also known to undergo isomerization processes that can help inform the discussion regarding alkenylnickel intermediates.

In 1979, Huggins and Bergman demonstrated that the rapid isomerization of alkenylnickel species can explain the observation of kinetic products with apparent anti stereoselectivity (Scheme 20).33 The authors elegantly showed that $\mathrm{Ni}(\mathrm{acac})\left(\mathrm{PPh}_{3}\right) \mathrm{Me}$ and $\mathrm{Ni}(\mathrm{acac})\left(\mathrm{PPh}_{3}\right) \mathrm{Ph}$ add to diphenylacetylene 2 and 1-phenylpropyne $\mathbf{6 0}$, respectively, to give the same kinetic product 61. Moreover, Huggins and Bergman went on to show that reactions with isotopically labelled components ( 60 and $d_{3}-\mathbf{6 0}$ ) undergo an initial addition reaction with measurable syn selectivity and then equilibrate to form a statistical mixture of isomers $\left(d_{3} \mathbf{- 6 1}\right)$. This report by Huggins and Bergman was the first to experimentally determine that anti-selective alkyne functionalization reactions could be explained by the isomerization of alkenylnickel species.

The report by Huggins and Bergman was also innovative because they carefully investigated the mechanism for alkenylnickel isomerization. ${ }^{33}$ The authors noted that direct unimolecular rotation about the alkenylnickel $\mathrm{C}=\mathrm{C}$ double bond was the most straightforward explanation conceptually, but ultimately discredited this mechanism based on experimental evidence (see below). ${ }^{33} \mathrm{~A}$ wide variety of mechanisms could explain the isomerization of alkenylnickel species. Several of these possible mechanisms are illustrated in Scheme 21. We suggest that mechanisms involving: (a) direct unimolecular rotation, (b) reversible nucleophilic attack, (c) reversible protonation, and (d) reversible bond homolysis are the most relevant for consideration here. This is not meant to be an exhaustive list of all possible isomerization mechanisms. Since direct unimolecular rotation about an alkenylnickel double bond is argu- ably the simplest mechanism for isomerization, it is discussed first.

Huggins and Bergman proposed that charge-separated resonance contributors might lower the barrier for unimolecular rotation about the alkenylnickel $\mathrm{C}=\mathrm{C}$ double bond since they would impart more single-bond character to these species (Scheme 21a). Often referred to using different terms (dipolar, ${ }^{30 b}$ bipolar, ${ }^{31 a}$ zwitterionic, ${ }^{31 b}$ and/or carbene ${ }^{31 c}$ ), similar resonance structures have been proposed to contribute to the isomerization of other alkenylmetal species. ${ }^{18,29-32}$ Huggins and Bergman proposed a resonance structure in which the metal center has significant $\pi$-acidity and accepts electron density from the alkenyl ligand. ${ }^{33}$ This is consistent with the final conclusion of Huggins and Bergman regarding the isomerization mechanism (see below).

Resonance structures proposed for alkenylrhodium and alkenylpalladium species are more typically represented with significant $\pi$-basicity and back-donation from the metal center to the alkenyl ligand. ${ }^{30,31}$ These representations are consistent with the established $\pi$-donating abilities of these metals. There are several instances in which the extent of isomerization can be directly correlated with the electron density present at the metal center. For example, alkenylrhodium complexes with substituted triphenyl-

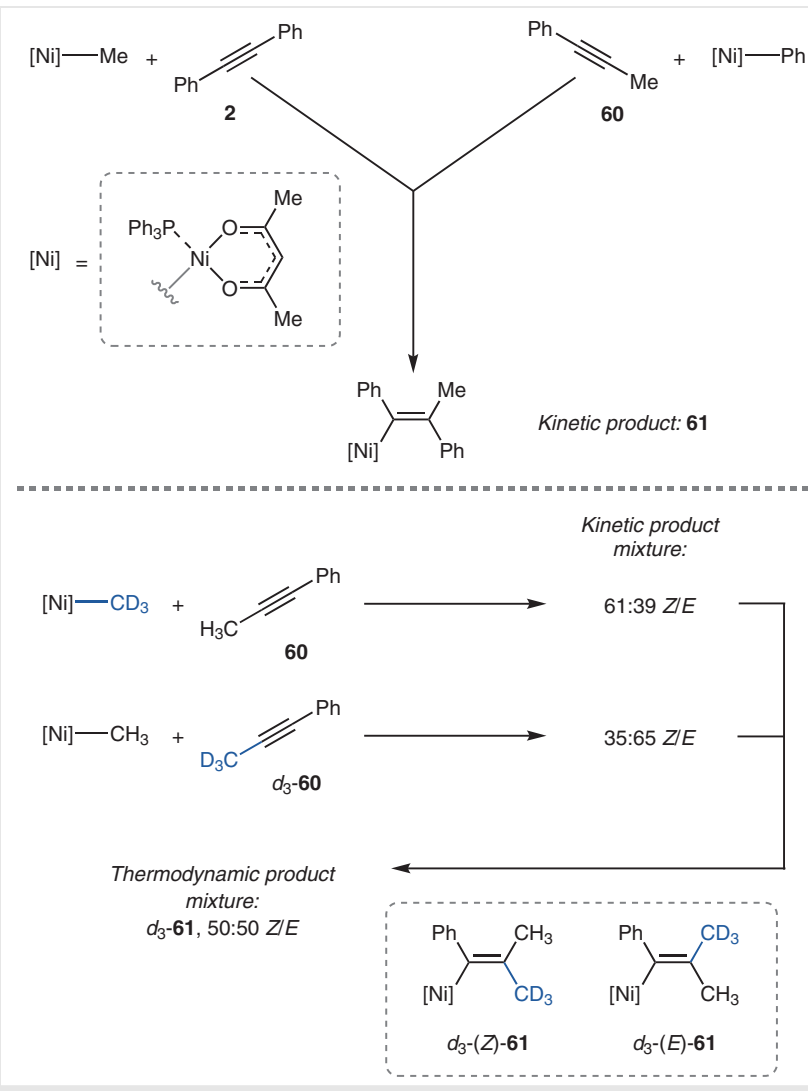

Scheme 20 Seminal studies on alkenylnickel isomerization ${ }^{33}$ 
(a) Direct unimolecular rotation:

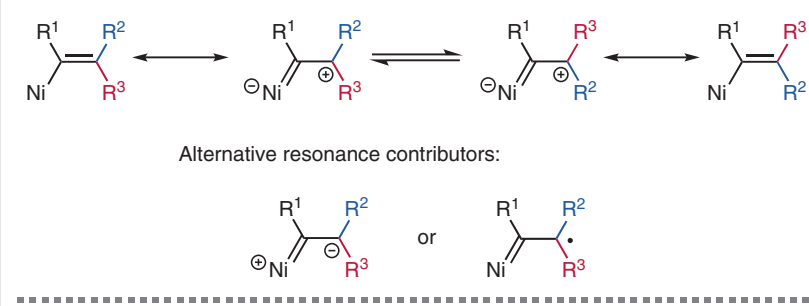

(b) Nucleophile-catalyzed isomerization (phosphines):
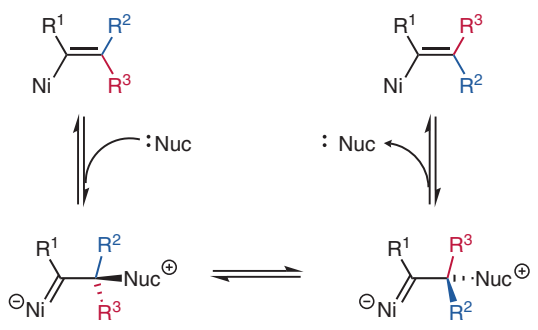

(c) Acid-catalyzed isomerization:

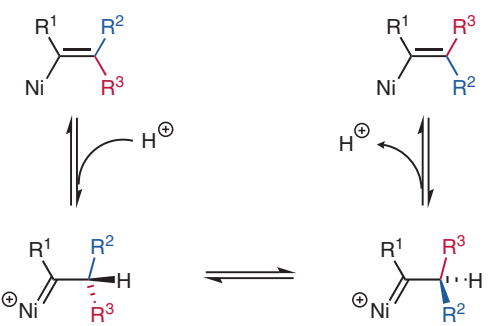

(d) Reversible bond homolysis:

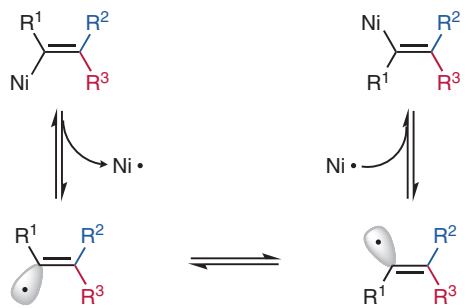

Scheme 21 Possible isomerization mechanisms for alkenylnickel species

phosphine ligands $\left.\left(\mathrm{P}_{6} \mathrm{C}_{6} \mathrm{H}_{4} \mathrm{X}\right)_{3}\right)$ undergo isomerization with rates reflecting the relative electron-donating ability of the phosphine ligand $\left(\mathrm{X}=\mathrm{F}<\mathrm{H}<\mathrm{OCH}_{3}\right){ }^{30 \mathrm{~b}}$ In other instances, isomerization can be directly linked to the $\pi$-accepting ability of the alkenyl ligand. Alkynes with conjugated carbonyl substituents will often undergo isomerization, while alkynes lacking these substituents are configurationally stable under identical conditions. ${ }^{30 a, b, 31 b}$

Catalytic intermediates in the $\mathrm{Ni}(\mathrm{I})$ oxidation state may facilitate isomerization in several of the difunctionalization reactions described above. $\mathrm{A} \mathrm{Ni}(\mathrm{I})$ complex would possess greater electron density compared to a $\mathrm{Ni}$ (II) complex, and that would presumably facilitate back-donation consistent with the examples above. The isomerization process observed by Huggins and Bergman occurred within the $\mathrm{Ni}(\mathrm{II})$ oxidation state, but the ancillary ligand was anionic $(\mathrm{acac}=$ acetylacetonate). That isomerization reaction was also found to be phosphine-catalyzed (see below). Importantly, a catalytic intermediate that is formally a $\mathrm{Ni}(\mathrm{I})$ complex may be more accurately described as a $\mathrm{Ni}(\mathrm{II})$ complex with a reduced (radical-anion) ligand. ${ }^{34}$ That electronic structure would resemble the Ni complexes studied by Huggins and Bergman more closely. It should be noted that Liu, ${ }^{17}$ Wilger, ${ }^{19}$ and Martin $^{26}$ have all independently reported alkenylnickel isomerization and each of these reports implicated $\mathrm{Ni}(\mathrm{I})$ species as key catalytic intermediates. Because $\mathrm{Ni}(\mathrm{I})$ species are odd-electron intermediates it may be prudent to consider resonance contributors that distribute spin density throughout the alkenyl ligand.

Huggins and Bergmans' study of alkenylnickel isomerization provided compelling evidence that the process was catalyzed by free phosphine ligand (Scheme 22). Reversible phosphine exchange was evident by NMR analysis of the $\mathrm{Ni}$ reactants $\mathbf{6 2}$. The rate of addition to alkynes was inversely proportional to the concentration of added phosphine. The structure of the phosphine ligand in the Ni species also affected the rate of addition. Those observations implied that ligand substitution to form $\mathbf{6 3}$ was at least partially ratelimiting in the carbonickelation process. Huggins and Bergman suggested an associative mechanism for alkyne/phosphine exchange. Since the observed products were formed by phosphine coordination to $\mathbf{6 4}$ after carbonickelation, it would be expected that the concentration of the ligand should have substantially influenced the observed stereoselectivity. However, the diastereomeric ratios observed for kinetic product mixtures displayed minimal dependence on the concentration of added phosphine. For example, the rates for addition reactions with added phosphine ligand displayed a linear dependence on $1 /\left[\mathrm{PPh}_{3}\right]$, but changing the added phosphine concentration one order of magnitude changed the diastereomeric ratio approximately $10 \%$. These observations were consistent with a mechanism in which free phosphine catalyzed the isomerization of the alkenylnickel species syn-64 to anti-64. In other words, if the alkenylnickel intermediate were capable of undergoing isomerization by a direct unimolecular pathway, then higher phosphine concentrations would be expected to favor the trapping of syn-64 (and the observed syn-65/anti-65 ratio). Huggins and Bergman envisioned a mechanism in which free phosphine could reversibly attack the alkenyl carbon atom $\beta$ to the metal center in $\mathbf{6 4}$, and thereby allow rotation around the $C_{\alpha}-C_{\beta}$ bond. ${ }^{33}$ A phosphine-catalyzed isomerization mechanism could be operating in many of the Ni-catalyzed reactions reported above. In catalytic procedures that do not require added phosphines, it may be possible that another nucleophilic species such as dissociated pyridyl ligand, halide anion, or base could participate in this manner. 


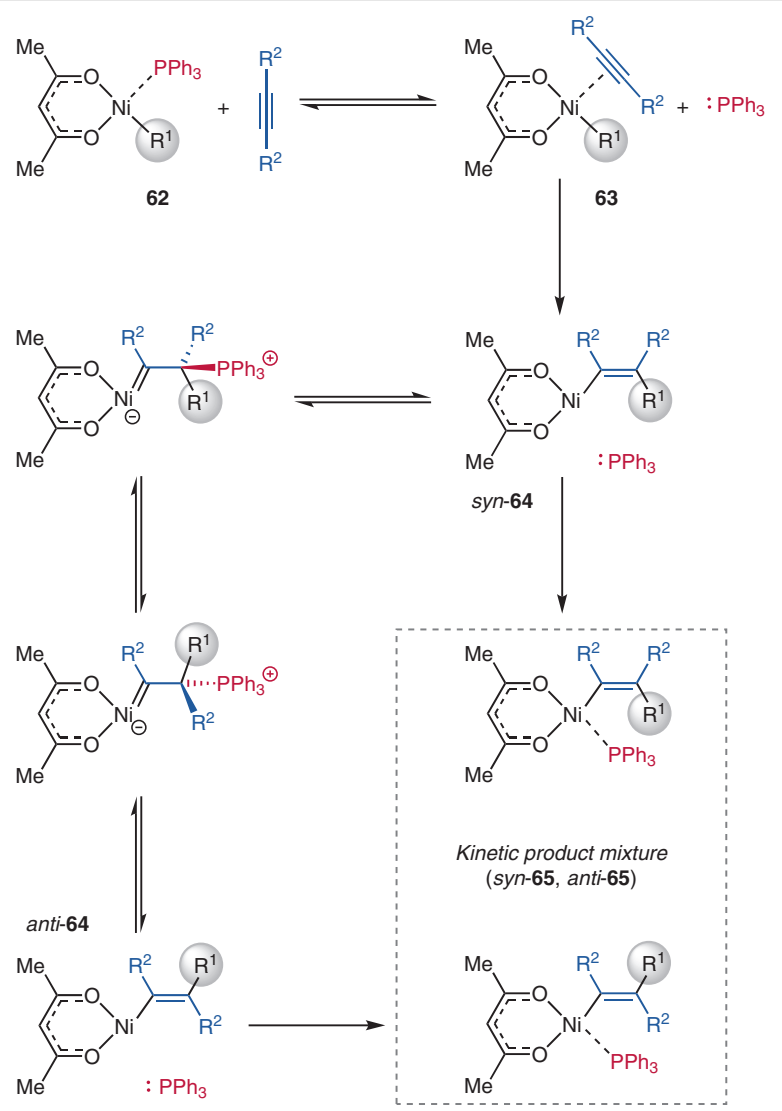

Scheme 22 Phosphine-catalyzed alkenylnickel isomerization ${ }^{33}$

Acid-catalyzed processes may also contribute to the isomerization of alkenylnickel species (Scheme 21c). Several of the Ni-catalyzed reactions reported above require protodenickelation as a product-forming step. Tanke and Crabtree hypothesized that acidic species could catalyze the isomerization of alkenyliridium intermediates within a hydrosilylation reaction. ${ }^{35}$ Control experiments that included exogenous base disproved this hypothesis. Since protonolysis is often a productive step in the reported anti-selective alkyne functionalization reactions catalyzed by $\mathrm{Ni}$, the effects of exogenous base would be challenging to interpret. Tanke and Crabtree eventually supported an isomerization mechanism that involved direct unimolecular rotation of an alkenyliridium intermediate. Nelson and Gagné later demonstrated that rapid proton transfer steps can interconvert alkenylplatinum regioisomers $\mathbf{6 6}$ and $d \mathbf{- 6 6}$ in an enyne cycloisomerization reaction (Scheme 23 ). ${ }^{13}$ One could envision a similar sequence of proton transfer steps leading to the stereochemical isomerization of an alkenylnickel species. In the example reported by Nelson and Gagné, deuterated acids left a residual isotopic label in the product $\mathbf{6 7}$. This type of deuterium-labeling experiment would be challenging to perform or uninformative in many of the Ni-catalyzed alkyne functionalization reactions described above.

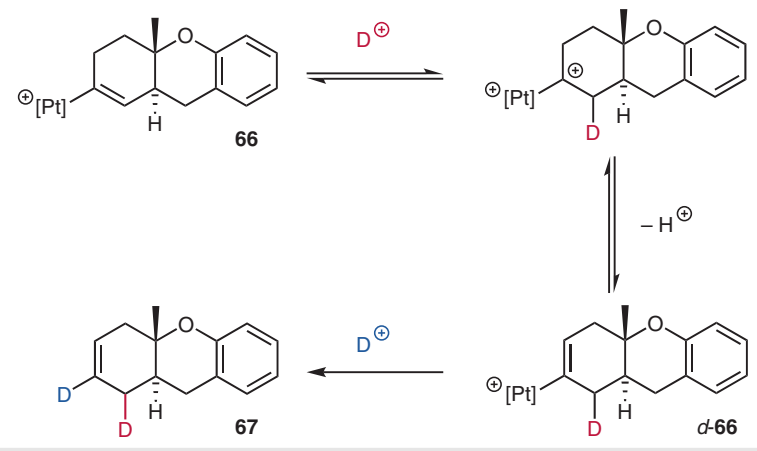

Scheme 23 Acid-catalyzed alkenylplatinum isomerization ${ }^{13}$

Martin et al. proposed that reversible $\mathrm{Ni}-\mathrm{C}$ bond homolysis could explain the isomerization of alkenylnickel species in the carboxylation reaction described in Section 4.3 (Scheme 24). ${ }^{26 a}$ Martin et al. proposed that after oxidative addition and alkyne migratory insertion with $\mathbf{4 8}$, an alkenylnickel species such as syn-68 may undergo bond homolysis to create a vinyl radical syn-69. The carbon-centered radical syn-69 would isomerize to anti-69, and then radical recombination with the $\mathrm{Ni}(\mathrm{I})$ center would produce anti-68 (and then eventually anti-49). Perhaps most interesting, the isomerization process appeared to be strongly dependent upon the choice of supporting ligand (neocuproine versus bathocuproine). Martin et al. suggested that redox-noninnocent ligand behavior may be partially responsible for this observation. ${ }^{34}$ The mechanistic studies reported by Wilger et al. indicated that irreversible $\mathrm{Ni}-\mathrm{C}$ bond homolysis did occur under catalytic alkyne hydroarylation conditions. However, the extent of reversible bond homolysis could not be assessed. Direct unimolecular bond rotation and reversible $\mathrm{Ni}-\mathrm{C}$ bond homolysis are perhaps the most challenging isomerization processes to differentiate. Detailed mechanistic studies, including crossover experiments with well-defined alkenylnickel complexes, should

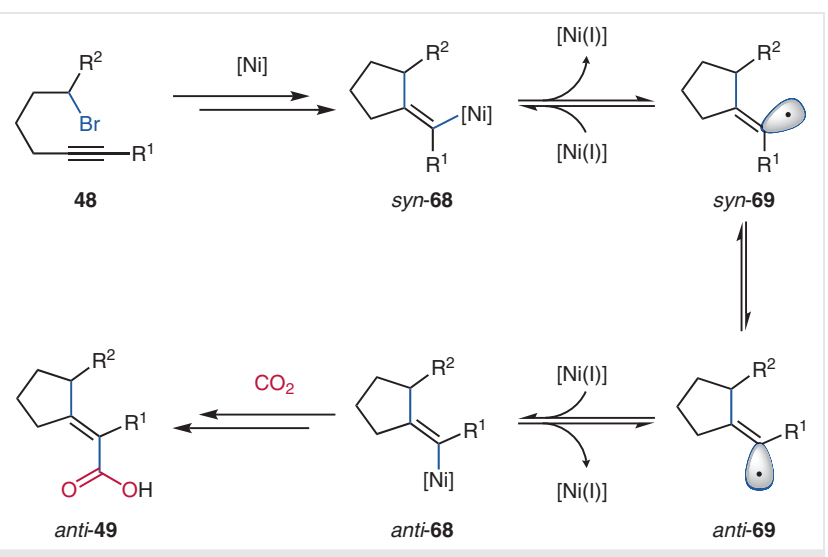

Scheme 24 Alkenylnickel isomerization via reversible bond homolysis $^{26 a}$ 
help to differentiate direct unimolecular rotation and reversible bond homolysis in the future.

\section{Conclusions}

A large sampling of recently reported $\mathrm{Ni}$-catalyzed antiselective alkyne functionalization reactions has been summarized. In many instances, the proposed mechanisms for these transformations have suggested alkenylnickel isomerization as the cause for their unusual stereoselectivity. Key outliers include the anti-selective intermolecular alkyne difunctionalization reactions reported by Nevado et al. Both of these mechanistic umbrellas hold promise for future reaction development. Because the isomerization of alkenylnickel species facilitates stereoselectivity in many of the examples described above, this topic was briefly reviewed as well (Section 6). Several possible mechanisms for alkenylnickel isomerization were described in the context of reported catalytic reactions. Further understanding these isomerization processes will lead to improvements in $\mathrm{Ni}$ catalyzed cross-coupling procedures and to the creation of new alkyne functionalization reactions.

Given the broad range of possible mechanisms that could explain alkenylnickel isomerization, we believe that further experimentation will greatly elucidate this field of study. As noted above, several of the isomerization mechanisms are very difficult to differentiate between. Numerous questions regarding the oxidation state of configurationally unstable species $(\mathrm{Ni}(\mathrm{I})$ versus $\mathrm{Ni}(\mathrm{II})$ ) remain. Other questions relate to the role that nucleophilic and acidic species might play in catalyzing isomerization. Although challenging, the synthesis and characterization of discreet alkenylnickel complexes should be pursued. Catalytic and stoichiometric control experiments with these complexes should help to fully define the relevant mechanisms. We hope this Short Review inspires further investigations in this area.

\section{Acknowledgment}

We would like to thank Professor Paul Knochel for inviting us to prepare this manuscript. Professor Wilger would like to thank Samford University, the Howard College of Arts and Sciences, and the Course Release for Research Product Completion (CRRPC) program for facilitating the preparation of this manuscript.

\section{References}

(1) For reviews concerning alkyne hydroarylation, see: (a) Nevado, C.; Echavarren, A. M. Synthesis 2005, 167. (b) de Haro, T.; Nevado, C. Comprehensive Organic Synthesis, 2nd ed; Knochel, P., Ed.; Elsevier: Amsterdam, 2014, 1621. (c) Boyarskiy, V. P.; Ryabukhin, D. S.; Bokach, N. A.; Vasilyev, A. V. Chem. Rev. 2016, 116, 5894.

(2) Murakami, K.; Ohmiya, H.; Yorimitsu, H.; Oshima, K. Org. Lett. 2007, 9, 1569.
(3) Yorimitsu, H.; Tang, J.; Okada, K.; Shinokubo, H.; Oshima, K. Chem. Lett. 1998, 27, 11.

(4) Shirakawa, E.; Masui, S.; Narui, R.; Watabe, R.; Ikeda, D.; Hayashi, T. Chem. Commun. 2011, 47, 9714.

(5) Murakami, K.; Yorimitsu, H.; Oshima, K. Org. Lett. 2009, 11, 2373.

(6) Stüdemann, T.; Knochel, P. Angew. Chem., Int. Ed. Engl. 1997, 36, 93.

(7) Xie, M.; Huang, X. Synlett 2003, 477.

(8) Lautens, M.; Yoshida, M. Org. Lett. 2002, 4, 123.

(9) (a) Oh, C. H.; Jung, H. H.; Kim, K. S.; Kim, N. Angew. Chem. Int. Ed. 2003, 42, 805. (b) Kim, N.; Kim, K. S.; Gupta, A. K.; Oh, C. H. Chem. Commun. 2004, 618. (c) Cacchi, S.; Fabrizi, G.; Goggiamani, A.; Persiani, D. Org. Lett. 2008, 10, 1597. (d) Xu, X.; Chen, J.; Gao, W.; Wu, H.; Ding, J.; Su, W. Tetrahedron 2010, 66, 2433. (e) Liu, S.; Bai, Y.; Cao, X.; Xiao, F.; Deng, G.-J. Chem. Commun. 2013, 49, 7501. (f) Liu, Z.; Derosa, J.; Engle, K. M. J. Am. Chem. Soc. 2016, 138, 13076. (g) Rao, S.; Joy, M. N.; Prabhu, K. R. J. Org. Chem. 2018, 83, 13707.

(10) (a) Jia, C.; Piao, D.; Oyamada, J.; Lu, W.; Kitamura, T.; Fujiwara, Y. Science 2000, 287, 1992. (b) Jia, C.; Lu, W.; Oyamada, J.; Kitamura, T.; Matsuda, K.; Irie, M.; Fujiwara, Y. J. Am. Chem. Soc. 2000, 122, 7252. (c) Lu, W.; Jia, C.; Kitamura, T.; Fujiwara, Y. Org. Lett. 2000, 2, 2927. (d) Jia, C.; Piao, D.; Kitamura, T.; Fujiwara, Y. J. Org. Chem. 2000, 65, 7516. (e) Jia, C.; Kitamura, T.; Fujiwara, Y. Acc. Chem. Res. 2001, 34, 633.

(11) (a) Reetz, M. T.; Sommer, K. Eur. J. Org. Chem. 2003, 3485. (b) Shi, Z.; He, C. J. Org. Chem. 2004, 69, 3669.

(12) Yanagihara, N.; Lambert, C.; Iritani, K.; Utimoto, K.; Nozaki, H. J. Am. Chem. Soc. 1986, 108, 2753.

(13) Nelsen, D. L.; Gagné, M. R. Organometallics 2009, 28, 950.

(14) (a) Shirakawa, E.; Takahashi, G.; Tsuchimoto, T.; Kawakami, Y. Chem. Commun. 2001, 2688. (b) Murakami, K.; Ohmiya, H.; Yorimitsu, H.; Oshima, K. Chem. Lett. 2007, 36, 1066. (c) Xue, F.; Zhao, J.; Hor, T. S. A. Chem. Commun. 2013, 49, 10121. (d) Dorn, S. C. M.; Olsen, A. K.; Kelemen, R. E.; Shrestha, R.; Weix, D. J. Tetrahedron Lett. 2015, 56, 3365.

(15) Robbins, D. W.; Hartwig, J. F. Science 2011, 333, 1423.

(16) (a) Babu, M. H.; Kumar, G. R.; Kant, R.; Reddy, M. S. Chem. Commun. 2017, 53, 3894. (b) Kumar, G. R.; Kumar, R.; Rajesh, M.; Reddy, M. S. Chem. Commun. 2018, 54, 759.

(17) Zhang, X.; Xie, X.; Liu, Y. Chem. Sci. 2016, 7, 5815.

(18) Lin, P.-S.; Jeganmohan, M.; Cheng, C.-H. Chem. Eur. J. 2008, 14, 11296.

(19) Barber, E. R.; Hynds, H. M.; Stephens, C. P.; Lemons, H. E.; Fredrickson, E. T.; Wilger, D. J. J. Org. Chem. 2019, 84, 11612.

(20) León, T.; Correa, A.; Martin, R. J. Am. Chem. Soc. 2013, 135, 1221.

(21) (a) Rosen, B. M.; Quasdorf, K. W.; Wilson, D. A.; Zhang, N.; Resmerita, A.-M.; Garg, N. K.; Percec, V. Chem. Rev. 2011, 111, 1346. (b) Lin, Q.; Diao, T. J. Am. Chem. Soc. 2019, 141, 17937.

(22) (a) Yamamoto, A.; Suginome, M. J. Am. Chem. Soc. 2005, 127, 15706. (b) Daini, M.; Yamamoto, A.; Suginome, M. Asian J. Org. Chem. 2013, 2, 968.

(23) Suginome, M.; Yamamoto, A.; Murakami, M. J. Am. Chem. Soc. 2003, 125, 6358

(24) Igarashi, T.; Arai, S.; Nishida, A. J. Org. Chem. 2013, 78, 4366.

(25) (a) Clarke, C.; Incerti-Pradillos, C. A.; Lam, H. W. J. Am. Chem. Soc. 2016, 138, 8068. (b) Yap, C.; Lenagh-Snow, G. M. J.; Karad, S. M.; Lewis, W.; Diorazio, L. J.; Lam, H. W. Angew. Chem. Int. Ed. 2017, 56, 8216. (c) Karad, S. N.; Panchal, H.; Clarke, C.; Lewis, W.; Lam, H. W. Angew. Chem. Int. Ed. 2018, 57, 9122. (d) Gillbard, S. M.; Chung, C.-H.; Karad, S. N.; Panchal, H.; Lewis, W.; Lam, H. W. Chem. Commun. 2018, 54, 11769. 
(26) (a) Wang, X.; Liu, Y.; Martin, R. J. Am. Chem. Soc. 2015, 137, 6476. (b) Börjesson, M.; Moragas, T.; Martin, R. J. Am. Chem. Soc. 2016, 138, 7504.

(27) (a) Li, Z.; García-Domínguez, A.; Nevado, C. J. Am. Chem. Soc. 2015, 137, 11610. (b) Li, Z.; García-Domínguez, A.; Nevado, C. Angew. Chem. Int. Ed. 2016, 55, 6938. (c) García-Domínguez, A.; Müller, S.; Nevado, C. Angew. Chem. Int. Ed. 2017, 56, 9949.

(28) (a) Shirakawa, E.; Yamasaki, K.; Yoshida, H.; Hiyama, T. J. Am. Chem. Soc. 1999, 121, 10221. (b) Xue, F.; Zhao, J.; Hor, T. S. A.; Hayashi, T. J. Am. Chem. Soc. 2015, 137, 3189. (c) Johnson, K. A.; Biswas, S.; Weix, D. J. Chem. Eur. J. 2016, 22, 7399. (d) Shimkin, K. W.; Montgomery, J. J. Am. Chem. Soc. 2018, 140, 7074.

(29) Burns, R. M.; Hubbard, J. L. J. Am. Chem. Soc. 1994, 116, 9514.

(30) (a) Booth, B. L.; Lloyd, A. D. J. Organomet. Chem. 1972, 35, 195. (b) Hart, D. W.; Schwartz, J. J. Organomet. Chem. 1975, 87, C11. (c) Michman, M.; Weksler-Nussbaum, S. J. Chem. Soc., Perkin Trans. 2 1978, 872. (d) Jones, W. D.; Chandler, V. L.; Feher, F. J.
Organometallics 1990, 9, 164. (e) Morimoto, T.; Yamasaki, K.; Hirano, A.; Tsutsumi, K.; Kagawa, N.; Kakiuchi, K.; Harada, Y.; Fukumoto, Y.; Chatani, N.; Nishioka, T. Org. Lett. 2009, 11, 1777. (31) (a) Zargarian, D.; Alper, H. Organometallics 1993, 12, 712. (b) Cacchi, S.; Fabrizi, G.; Marinelli, F.; Moro, L.; Pace, P. Tetrahedron 1996, 52, 10225. (c) Krasovskiy, A.; Lipshutz, B. H. Org. Lett. 2011, 13, 3818.

(32) Werner, H.; Weinand, R.; Knaup, W.; Peters, K.; von Schnering, H. G. Organometallics 1991, 10, 3967.

(33) (a) Huggins, J. M.; Bergman, R. G. J. Am. Chem. Soc. 1979, 101, 4410. (b) Huggins, J. M.; Bergman, R. G. J. Am. Chem. Soc. 1981, $103,3002$.

(34) (a) Hu, X. Chem. Sci. 2011, 2, 1867. (b) Lyaskovskyy, V.; de Bruin, B. ACS Catal. 2012, 2, 270. (c) Powers, D. C.; Anderson, B. L.; Nocera, D. G. J. Am. Chem. Soc. 2013, 135, 18876.

(35) Tanke, R. S.; Crabtree, R. H. J. Am. Chem. Soc. 1990, 112, 7984. 